\title{
Editorial
}

\section{Disability and Capacity Building of Rehabilitation Health Workforce in Low and Middle Income Countries}

\author{
Received: July 30, 2019 Accepted: August 20, 2019 \\ doi: https://doi.org/10.3329/jemc.v9i3.43242
}

Disability is a global public health issue. More than one billion people currently experience disability, which equates to approximately $15 \%$ of the world's population. Disability disproportionately affects marginalized, disadvantaged or at-risk populations such as women, older people, and people who are poor. Children from poorer households, indigenous populations, and those in ethnic minority groups are also at significantly higher risk of experiencing disability. Lower income countries have a higher prevalence of disability than higher income countries. ${ }^{1}$ There is strong evidence for a link between disability and poverty in low and middle income countries and an urgent need for further research and policy action to break the cycle. ${ }^{2} \mathrm{~A}$ cross pilot survey of rehabilitation health professionals from Pakistan, Morocco, Nigeria and Malaysia captured assessment of clinical skills required in rehabilitation. The findings highlight core skills and gaps in training, education, and available funding. The survey recommended that investment in capacity-building of rehabilitation health workforce will allow professional skill development strategies to meet particular needs described by participants to deliver high-quality services. ${ }^{3}$ Bangladesh, a low resource country in South Asia, launches rehabilitation medicine service in some 50 years back, but a snail pace progress creates a sordid saga in this world's most densely populated country. The structures of primary health care delivery systems in Bangladesh have no provision of priority care for disabled and have scarcity of skilled manpower to address the disabled. In Bangladesh, like many other low and middle income countries (LMICs) there is a shortage of workers with appropriate rehabilitation skills, resulting in task-shifting practices. For rehabilitation services in many LMICs, there are challenges within operational healthcare systems in terms of policy, funding structure/infrastructure, capacity, human and physical resources, and technology. ${ }^{4-6}$

A core set of clinical skills need to be developed for health-related community-based rehabilitation (CBR) work in LMICs. Important aspects are assessment, monitoring and reporting, behavioral and cognitive interventions, education, gait training, group work, home-based rehabilitation, manual therapy, facilitation techniques, positioning, prescription of strengthening exercises, prescription of stretching programs, provision of aids, assistive devices and technologies, psychosocial support, recreational therapy, self-care, sensory interventions, supervision, vocational rehabilitation and working with families.

CBR has improved the quality of life, access to medical services, functional independence, autonomy, community inclusion and empowerment of people with disabilities (PWD) in LMICs in the Asia-Pacific region. However, challenges in the implementation of CBR remain. These include lack of awareness and understanding of CBR, and physical, environmental, socio-economical and personal barriers.

\section{Bangladesh perspectives}

In Bangladesh there is no structured community-based rehabilitation services rendered by primary health care system. Some non-government organizations and Ministry of Social Welfare are providing scattered services and these are not context- or task-specific or lacking clinical skills. We have found nine government and 143 non-government organizations who are working with PWD. They are working independently in different regions of the country with different areas of disability. Their fields of activities are not uniform and are not covering all aspects of a disabled. Some are addressing medical, educational, vocational, social and CBR and some are working with financial support and assistive devices. These services are not consistent with WHO approved health component of CBR matrix. ${ }^{9}$

National Disabled Development Foundation, the largest one supported by Ministry of Social Welfare started its activity in 2009-2010 with centers in five districts only. Their service and support centers are now raised to 103 in 64 districts and 39 upazillas (sub-districts) during 
last few years. Further, an autism corner has been launched in every center. These centers are providing free medical rehabilitation services like physiotherapy, occupational therapy and assistive devices. ${ }^{10,11}$ Clinical skills and covering areas of rehabilitation health workforce have not been substantiated. A physiatrist or rehabilitation specialist can better monitor their clinical skills and health needs of a disabled.

\section{Disability identification and categorization}

Countrywide disability detection survey program is identifying the type and cause of disability and categorizing the disabled according to prescribed criteria, which equates the health and other needs of disabled persons. The present system of applying to the committee for inclusion of disability status is not appropriate rather survey workers should go to each house and bring the disabled to the local center for identification and categorization. There are national, district and sub-district committees to protect and preserve the rights of disabled persons. They are supposed to identify and categorize the disabled citizens nationwide. A physiatrist or at least a doctor trained in physical medicine must be included in each committee to see the health need of a disabled and appropriate referral. A doctor can also ensure inclusion and exclusion criteria of disability.

With the financial support of UNICEF Bangladesh, a web-based disability information database is about to be developed to ensure the overall development of the PWDs after they are being detected by the doctors. ${ }^{10}$

We need to address the capacity building of rehabilitation health workforce at the community level. We should train the health workforce for clinical skills so that they can apply their knowledge to the health needs of the disabled. Some organizations are working independently on different components of CBR, but health components are inadequately addressed. Community-based approach to different components of primary health care should be integrated with community-based rehabilitation (CBR)'s structured medical care which includes optimizing functions by medical treatment, therapy, assistive devices etc. These concepts will be more financially viable than establishing separate CBR services. ${ }^{12}$

Funding and planning are major hindrances in capacity building of rehabilitation health workforce.
Bangladesh, a growing economy in South Asia also has rising health indexes but rehabilitation services are squeezed at the bottom of cauldron. To sustain the growing trend in health indexes, medical rehabilitation services at the community level need to be urgently implemented with comprehensive approach to people at low resource outset. Community-based rehabilitation services can better reach the marginalized population and should follow the WHO guided CBR matrix. Large number of rehabilitation health workforce need to be recruited and trained to reduce the burden of disability in the society. Physiatrists or rehabilitation specialists must be involved in all steps of medical rehabilitation services to ensure clinical skills to service providers. Improving the quality of life of millions of disabled and bringing them into mainstreams of development in LMICs is the crying need of time.

\section{Md. Shahidur Rahman}

Professor, Department of Physical Medicine and

Rehabilitation, Bangabandhu Sheikh Mujib Medical University, Dhaka

Email: shahidurpmrbd@gmail.com

\section{References}

1. Gutenbrunner $\mathrm{C}^{1}$, Negrini S, Kiekens C, Zampolini M, Nugraha B. The Global Disability Action Plan 2014-2021 of the World Health Organisation (WHO): a major step towards better health for all people with disabilities. Chance and challenge for Physical and Rehabilitation Medicine (PRM). Eur J Phys Rehabil Med 2015; 51(1): 1-4.

2. Banks LM, Kuper H, Polack S. Poverty and disability in low- and middle-income countries: a systematic review. PLoS ONE 2017; 12(12): e0189996. Available at: $\quad$ https://doi.org/10.1371/journal.pone.0189996. Accessed July 2019.

3. Khan F, Amatya B, De Groote W, Owolabi M, Syed IM, Hajjoui A et al. Capacity building in clinical skills of rehabilitation workforce in low and middle income countries. J Rehabil Med 2018; 50: 472-479.

4. Khan F, Amatya B, Avirmed B, Yi YK, Shirmen B, Abbott $\mathrm{G}$ et al. World Health Organization Global Disability Action Plan: the Mongolian perspective. J Rehabil Med 2018; 50: 388-366.

5. Khan F, Amatya B, Mannan H, Burkle FM, Galea MP. Rehabilitation in Madagascar: challenges in implementing the World Health Organization 
Disability Action Plan. J Rehabil Med 2015; 47: 688696.

6. Khan F, Amatya B, Sayed TM, Butt AW, Jamil K, Iqbal W et al. World Health Organisation Global Disability Action Plan 2014-2021: challenges and perspectives for physical medicine and rehabilitation in Pakistan. J Rehabil Med 2017; 49: 10-21.

7. O'Dowd J, MacLachlan M, Khasnabis C, Geiser P. Towards a core set of clinical skills for health-related community based rehabilitation in low and middle income countries. Disabil Community-Based Rehabil Inclusive Develop 2015; 26: 5-43.

8. Cayetano RDA, Elkins J. Community-based rehabilitation services in low and middle-income countries in the Asia-Pacific region: successes and challenges in the implementation of the CBR matrix. Disability, CBR and Inclusive Development 2016; 27(2). Available at: www.dcidj.org. Accessed July 2019.

9. Community-Based Rehabilitation: CBR Guidelines Pck Pap/CD Edition by World Health Organization (Author)ISBN-13: $\quad$ 978-9241548052 ISBN-10: 9241548053. Introductory booklet, Helsinki, 2003.

10. National disabled development foundation, Ministry of Social Affairs. Available at: www.mosa.gov.bd. Accessed August 2019.

11. Rahman MS. Community-based rehabilitation in Bangladesh, health components need to be integrated with primary health care. J Enam Med Col 2018; 8(1): 41-45. 